American Journal of Applied Sciences 3 (2): 1715-1718, 2006

ISSN 1546-9239

(C) 2006 Science Publications

\title{
An Online Website for Tutoring and E-Examination of Economic Course
}

\author{
${ }^{1}$ Ibrahiem M. M. EL Emary and ${ }^{2}$ Jihad. A. A. Abu Al Sondos \\ ${ }^{1}$ Faculty of Engineering, Amman AL Ahliyya University, Amman, Jordan \\ ${ }^{2}$ Faculty of Planning and Administration, Al Balqa Applied University, Amman, Jordan
}

\begin{abstract}
This study aimed to present a novel software tool can be used for online examination and tutorial application of the syllabus of economic course. Also, among the main interests of this paper is to produce a software through it we make sure that students have studied all the concepts of economics. So, the proposed software is structured from two major modules: The first one is an online website to review and make self-test for all the material of economic course. The second part is an online examination using a large database bank of questions through it the level of students can be evaluated immediately and some statistical evaluations can be obtained. The developed software offers the following features: 1) Instructors could add any further questions to maximize the size of the bank of questions. 2) Different examinations for each student with randomly selected questions from the bank of questions can be done. 3) Different reports for the instructors, students, classes...etc can be obtained. 4) Several students can take their exams simultaneously without any problem inside and outside their campus. The proposed software has been designed to work base on the client server architecture.
\end{abstract}

Key words: JDBC, SQL, URL, DBMS, E-R, SHTML

\section{INTRODUCTION}

As schools around the word establish connections to the Internet and teachers and students gain proficiency with navigating through the vast quantity of readily available information, the true educational potential of the World Wide Web can finally begin to be understood. The Web can be a dynamic tool capable of assisting educators in propelling learning to exciting and compelling levels and of bringing education to any students, any where, at any time. Students can learn from experiences and communication that would never be possible within the scope of an isolated classroom. But instructional resources on the Web should never be mistaken as substitutes for the skill and intuition of human teachers, or even thought of as replacements for traditional methods of instruction. Instead, these resources, when used appropriately, should be considered as rich enhancements of a complete educational plane $\mathrm{e}^{[1,2,6]}$.

In this study, we are concerned with presenting some type of new software enable the students to review all the materials of economic course as well as enabling the teachers to make their examinations in an online approach to evaluate the level of their students. To achieve this goal, we present this paper which is organized from various sections given by: section two describes the used software and hardware tools. Section three covers the proposed system components. In section four, we present some of case studies that are obtained as a result of executing the proposed system (bank of Questions). Section five deals with conclusions and future works.

The used S/W and H/W tools: This section is concerned with the tools that are used for implementing the proposed software for tutoring and examining online the Economic course. This section is subdivided into three subsections; the first one deals with the reasons of programming with Java. The next one describes some of capabilities that exist in servlet toolbox. The third subsection discusses the database management systems in view point of various jobs as: purpose of the database systems, database types and access database systems.

Reasons for programming with JAVA: Java is certain to become the language of choice in the new millennium for implementing Internet-based applications and any other software for devices that communicate over a network. Java provides an attractive package for advancing the state of programming language education, especially at the introductory and intermediate levels. Java programming offers us with various major benefits among it the following capabilities which are required for various applications ${ }^{[3]}$ :

* User interface (GUIS) which use multimedia graphical capabilities of graphics, images, animation, audio and video.

* Run on the internet and the World Wide Web and communicate with other applications. 
* Take advantages of the flexibility and performance improvements of multithreading.

* Are not limited the desktop or even to some local computer network, but that can integrate Internet components and remote database as well.

* Can be written quickly and correctly in a manner that takes advantages of a world of reuse of rebuilt software components, which want easy an access, to a growing universe of reusable software components.

Servlet toolbox: Java servlets are the Java solution for providing Web-based services. They provide a very similar interface for interacting with client queries and providing server responses. As such, discussion of much of the input and output in terms of HTML will overlap. Java Servlets interact with the user through HTML forms. Input to servlet programs is passed to the program using Web forms. Forms include text fields, radio buttons, check boxes, pop up boxes, scroll tables and the like ${ }^{[4,5]}$. Thus receiving input is a two step process:

We must create an HTML document that provides forms to allow users pass information to the server and our Servlet program must have a means for parsing the input data and determining the action to be taken. This mechanism is provided through Java Servlets. Our Servlet toolbox contains various activities given by:

* Servlet setup

* HTML forms as interface

* SHTML

* $\quad$ Server Side Input Handling by Java

* Java output

* Java Database connectivity- JDBC

* Establishing a connection

* Handling errors with exceptions

Database management system: A database management system (DBMS) consists of collection of interrelated data and a set of programs to access those data. The main goal of a DBMS is to provide an environment that is both convenient and efficient to user in retrieving and storing database information. Database systems are designed to manage large bodies of information. The management of data involves both the definition of structures for the storage of information and the provision of mechanisms for the manipulation of information.

Our proposed software system is based on using a relational database. The relational database such as my SQL, Microsoft SQL, server and Oracle have a much more logical structure in the way that it stores data. Tables can be used to represent real world objects, with each field acting like an attribute. For example, a table called books could have the columns title, author and ISBN, which describe the details of each book where each row in the table is a new book.
Relational database also have functions "built in" that helps in retrieving, sorting and editing the data in many different ways. These functions save script designers from having to worry about filtering out the results that they get and so can go quite some way to speeding up the development and production of web applications.

Access gives developers the tools they need to build powerfully, sophisticated Microsoft SQL server database solutions within the familiar access interface. Microsoft provides us by valuable Tools on the Web, such as templates, tools tips and updates that help us work faster. We take advantages of powerful new publishing tools that enable us to export both data and formatting for display on the Web. Interact with our data on the Web, We can build powerful data access pages that enable us to easily open, view and update live data within a Web browser in the office or on the road.

The proposed system components: We present the major components that structure our system. These major components consist of:

* Data description, which is concerned with students data, student answers, instructors data, questions with their answers, subject data, student test, students final grades and login. All the above data are putted in tables.

* Data model, this can be represented through the E$\mathrm{R}$ diagram that relate various relations with each others.

* List of activities, Here we present our various designed forms which are responsible for: Administration login page, Instructor page, update instructor page, Delete instructor page, Find instructor page, subject page, add subject page, update subject page, delete subject page, find subject page, student page, add student page, update student page, delete student page, find student page, instructor login page, question page, add question page, update question page, delete question page, find question page, grade distribution page, add grades distribution page, update grades distribution page, delete grade distribution page, find grade distribution page, report page, question report page, student login page, SWE tutorial page, Test page and change student password page. Figs. 1-3 illustrate some examples of these pages: instructor page, student page and administration page.

Bank of questions of economics course: The following are examples of the economic databank questions, which used by the instructors to teach their students and to train them how to use the tutorial \& examination as practical assignments. 
The concept of opportunity cost is based on the principle of:
a) Consumer spending
b) Wealth
e)Individuality
c) Poverty
d) Scarcity

answer questions $2-3$ :

\begin{tabular}{lll}
\hline Slices of Pizza & Total & Total Benefit \\
\hline 1 & $\$ 1.50$ & $\$ 4.00$ \\
2 & $\$ 3.00$ & $\$ 7.00$ \\
3 & $\$ 4.50$ & $\$ 9.00$ \\
4 & $\$ 6.00$ & $\$ 10.50$ \\
5 & $\$ 7.50$ & $\$ 10.75$ \\
\hline
\end{tabular}

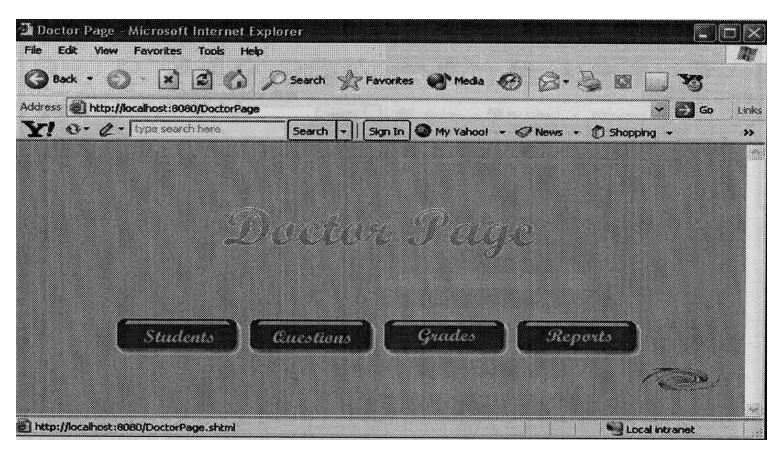

Fig.1: The instructor page

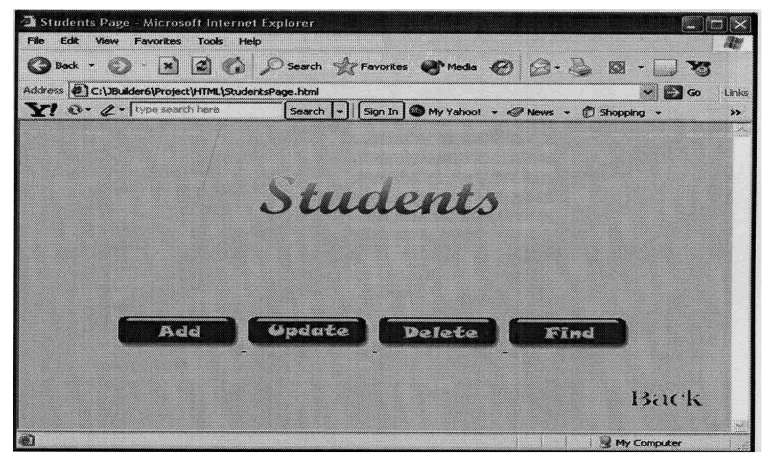

Fig.2: The student page

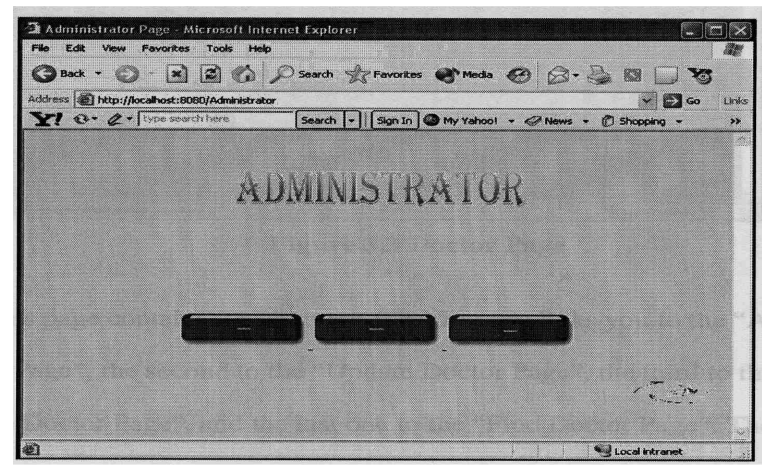

Fig. 3: The administrator page

What is the marginal cost of the second slice of Pizza? a) $\$ 3.0$ b) $\$ 1.5$ c) $\$ 7.00$ d) $\$ 4.50$ e) Not enough information provided.
What is the marginal benefit of the fourth slice of Pizza?
a) $\$ 6.00$ b) $\$ 10.50$ c) $\$ 1.50$ d) $\$ 4.50$ e) Not enough information provided.

\section{According to the law of supply:}

a) Anything that is supplied will be purchased.

b) If the price is low, any firm will sell the product.

c) All suppliers must abide by a set of common ethics.

d) The higher the price, the larger the quantity supplied.

e) The higher the price, the lower the quantity supplied.

Marginal utility is the:

a) Extra consumption divided by the amount of pleasure gained from the consumption.

b) Enjoyment obtained by consuming all of a good.

c) Total satisfaction of the last unit consumed.

d) Average happiness from consuming some number of goods.

e) Additional happiness gained by consuming one more unit of a good.

All else equal, a decrease in demand leads to:

a) Increased price and increased quantity.

b) Decreased price and decreased quantity.

c) Decreased price and increased quantity.

d) Increased price and decreased quantity.

e) None of the above answer is correct.

Which of the following statements is true?

a) In the short run, a firm decides what size and type of facility to build.

b) In the short run, a firm decides how much output to produce in the current facility.

c) In the long run is a period of time exceeding five years or more in length.

d) The short run refers to a short period of time, usually one year or less.

e) None of the above answer is correct.

A monopolist will choose a level of output that sets:

a) The price equal to the marginal cost.

b) Marginal cost greater than marginal revenue.

c) Marginal revenue greater than marginal cost.

d) Marginal revenue equal to marginal cost.

e) Marginal cost equal to the market demand curve.

Which of the following principles does the firm use to determine how many workers to hire?

a) The principle of diminishing returns.

b) The reality principle.

c) The principle of opportunity cost.

d) The marginal principle.

e) None of the above answer is correct. 
Traditionally, the government regulates the level of pollution with a:
a) Pollution tax.
b) Command - and - control policy.
c) Subsidy.
d) Marketable pollution permits system.
e) Spillover cost.

Which of the following principles does the firm use to determine how many workers to hire?
a) The reality principle.
b) The principle of diminishing returns
c) The marginal principle.
d) The principle of opportunity cost.
e) None of the above answer is correct.

If prices increase but the level of national output is held constant, then nominal GDP ---- And real GDP ---------.
a) Increase, Increase.
b) Increase, does not change.
c) Does not change, decrease.
d) Decreases, decreases.
e) Increase, decrease.

If the cost of a basket of goods is $\$ 125$ in $1989, \$ 135$ in 1990 and $\$ 150$ for 1991 , assuming 1991 is the base year, the CPI for 1989 is:
a) 90
b) 100
c) 83
d) 93
e) 120

If John quits his job to find a new job in a different city, John is considered
a) Technically unemployed.
b) Structurally unemployed.
c) Cyclically unemployed.
d) Frictionally unemployed.
e) Naturally unemployed.

Suppose that you have a college degree but the only work that you can find is driving a taxicab. What is this called?

a) Frictional unemployment.

b) Cyclically unemployment.

c) Underemployment.

d) A discouraged worker.

e) Structurally unemployment.

If $\mathrm{C}=200+0.75 \mathrm{Y}$ and $\mathrm{I}=50$, then the equilibrium level of output is (assume no government or foreign sectors).
a) 1000
b) 200
c) 267
d) 750
e) 500

The ratio of changes in output to changes in spending is known as
a) The marginal propensity to consume.
b) The multiplier.
c) The marginal propensity to import.
d) The marginal propensity to save.
e) The consumption function.

If the nominal interest rate is $8 \%$ and the inflation rate is $3 \%$, then the real interest rate is
a) $11 \%$
b) $-5 \%$
c) $5 \%$
d) $8 \%$
e) $-3 \%$

If nominal wages increase by $7 \%$ while the inflation rate is $3 \%$, then real wages
a) Increase by $10 \%$
b) Increase by $7 \%$
c) Decrease by $3 \%$
e) Decrease by $7 \%$.
d) Increase by $4 \%$

If $\mathrm{Y}=200+2 \mathrm{X}$, what is the slope of this line?
a) 20 b) 100
c) 200
d) $1 / 2$
e) 2

\section{CONCLUSION}

This study is interested in developing novel software capable of teaching the course of Economics online. Also, of the main interest of this paper the capability of making an online examination for the graduated student through a data bank resident in it a large number of questions and various answers, only the student select the appropriate answer to each question. The proposed software designed to work based on the client server architecture, so that several students can take their exams simultaneously without any problem inside and outside their campus.

\section{REFERENCES}

1. Barron, A.E., 1996. The internet: Ideas, Activities and Resources. Tampa, Fl: Florida Center for Instructional Technology.

2. Berenfeld, B., 1996. Linking students to the infoshere. T. H. E. Journal.

3. Tobiason, K., 1997. Tailoring the Internet to Primary Classroom. Technology Connection.

4. Nicholson, D., 1996. Class Projects on the Internet Education in Science.

5. Harrington-Lucker, D., 1997. Web-High. Electronic School.

6. Gary, B., 2002. Using technology in the classroom. A Pearson Education Company, Boston. 